\title{
Influences on tetanus immunization in accident and emergency
}

\author{
A. MONTAGUE \& E. GLUCKSMAN
}

Accident and Emergency Department, King's College Hospital, Denmark Hill, London SE5

\section{SUMMARY}

We studied the casualty records of 479 patients with open skin injury arriving over 2 single weeks, 3 months apart, to assess adequacy of adherence to protocols for active immunization against tetanus. 234 patients were treated correctly. In 114 cases immunization was insufficient or tetanus was not mentioned at all; in 29 cases immunization was excessive and 102 records were ambiguous and no conclusion could be drawn. There was no evidence in junior doctors' management indicating learning over 3 months but the mention of tetanus by a triage nurse was associated with a highly significant increase in the number of records showing correct treatment.

There is a persistent high error rate in tetanus immunoprophylaxis despite a department manual, an induction course, and conspicuously displayed treatment protocols. More individual feedback seems required but the unexpected benefit from assessment by a triage nurse may have greater impact in reducing treatment errors.

\section{INTRODUCTION}

It is estimated there are 50 cases of clinical tetanus each year in England and Wales (Public Health Laboratory Service, 1985) and reports of sensitivity to tetanus toxoid are few (Editorial 1985).

The aim of this study was to establish the rate of correct tetanus immunization within out department, with particular reference to factors increasing awareness of guidelines and whether existing training within the department improved correct immunization treatment.

Correspondence: $\operatorname{Dr}$ E. Glucksman, Accident and Emergenc Department, King's Hospital, Denmark Hill, London SE5, England. 
We examined the records of the Accident and Emergency department of London teaching hospital treating 80000 patients per year to assess how weff casualty officers follow guidelines for tetanus immunization and also what factor $\overrightarrow{\mathbb{P}_{2}}$ influence their decisions about immunoprophylaxis. The department's tetanus protection protocol contains guidance on wound treatment as well as passive andf

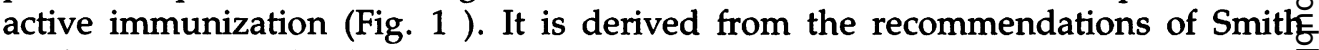
et al. in 1975. Only that part relating to active immunization was considered iro this study.

\section{PATIENTS AND METHODS}

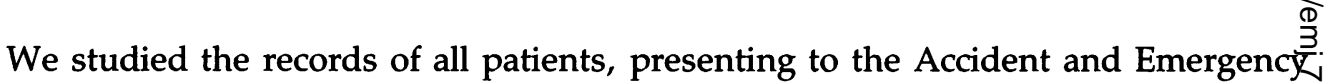
department during 2 separate weeks with a new open skin injury. The weeksi studied were the first and fourteenth of the casualty officers appointment, comळ mencing in February 1987.

The following information was extracted:

(1) Identification: age; date and time of arrival; nature of wound; name of examining doctor

(2) History: In particular a mention of tetanus immune status by the doctor o nurse attending the patient

(3) Treatment: a full course, a single dose of tetanus toxoid, or none.

Based on the department's protocol treatment was assessed as follows:

Correct treatment

Incorrect treatment

\section{Uncertain}

\section{status}

- a full history followed by appropriate immunization

- toxoid given unnecessarily (full course or booster)

- booster given when course required

- toxoid omitted when required

- no reference to tetanus immunization or treatment

It was not assumed that any patient had recieved the scheduled childhood. immunizations. Casualty cards contained no preprinted reference to immuniza tion. No specific feedback to casualty officers about this aspect of wound manage ment was given during the study periods.

\section{RESULTS}

A total of 479 patients were included in the study, 242 in the first week and 237 in the fourteenth. 377 had sufficient history for treatment to be considered as correct: or incorrect.

Overall $234(49 \%)$ were correctly treated (121 in February and 113 in May) and $143(30 \%)$ incorrectly treated (71 in February and 72 in May). $102(21 \%)$ patient had insufficient history and are included in the 'uncertain' group. 
All Wounds Receive

Surgical Toilet

Wounds that are less than hours old, Clean,

Other wounds non-penetrating and with Negligible Tissue Damage

\begin{tabular}{|c|c|c|c|}
\hline$\underset{\mathrm{A}}{\text { Immunity Category }}$ & $\begin{array}{l}\text { Treatment } \\
\text { Nothing more required }\end{array}$ & $\begin{array}{c}\text { Immunity Category } \\
\mathrm{A}\end{array}$ & $\begin{array}{l}\text { Treatment } \\
\text { Nothing more required }\end{array}$ \\
\hline B & Toxoid 1 dose & B & Toxoid 1 dose \\
\hline C & Toxoid 1 dose & C & $\begin{array}{l}\text { Toxoid } 1 \text { dose } \\
+ \text { Human tetanus } \\
\text { immunoglobulin }\end{array}$ \\
\hline D & Toxoid complete course & D & $\begin{array}{l}\text { Tetanus } \\
\text { complete course } \\
+ \text { Human tetanus } \\
\text { immunoglobulin }\end{array}$ \\
\hline
\end{tabular}

A: Has had a complete course of toxoid or a booster dose within the past 5 years.

B: Has had a complete course of toxoid or a booster more than 5 and less than 10 years ago.

C: Has had a complete course of toxoid or a booster dose more than 10 years ago.

D: Has not had a complete course of toxoid or immunity status is unknown.

Fig. Tetanus treatment protocol employed in the study

Six doctors worked in both of the weeks and their success in following the protocol was analysed in terms of percentage of patients correctly treated. There was no significant difference between the study periods, in respect of correct treatment or adequacy of history taken. The likelihood of correct treatment did not vary significantly with time of arrival or with the patient's age.

A total of 24 cases of burns were seen; $19(79 \%)$ were wrongly treated, $3(12 \%)$ were correctly treated and $1(4 \%)$ was uncertain.

Excessive treatment was given to $29(6 \%)$ patients with a history of immunization. 13 of 175 who were fully immunized were further immunized, 11 with a single dose and 2 with a complete course. $16(22 \%)$ of 72 with primary immunization were improperly given a complete course.

A total of 114 patients $(24 \%)$ received inadequate treatment. Of their records 101 (217.) contained no reference to tetanus by the medical staff and tetanus immunization was not given. A total of 13 showed treatment to be required but not given, including 7 given a single dose of toxoid where a course was indicated, 3 were not given toxoid where a booster was required and 3 without primary immunization were left untreated. This also included 9 in whom no history was obtained because of their clinical condition and no treatment given. History of immunization and correctness of treatment was uncertain in 102 patients. Seventy-six received single doses and 20 received a full course of tetanus toxoid.

In 230 cases $(\mathbf{4 8 \%})$ the triage nurse included a reference to tetanus on the record at the time of the initial interview. Of such records $154(80 \%)$ went on to contain 
sufficient history and show correct treatment. Of the 114 inadequately treated patients only 17 had a reference to tetanus by the nurse. A nurse's reference to tetanus was present in only $8(5 \%)$ of the 114 cases inadequately treated (Table 1). The nurse's influence on adequate treatment is highly significant $\left(\chi^{2}=77 \cdot 489\right.$; $P<0.000001)$.

\section{DISCUSSION}

Tetanus occurs due to the elaboration of toxin by Clostridium tetani, an obligate anaerobe, in devitalized tissue. Therefore proper wound toilet is essential and administration of antitoxin to the non-immune reduces the risk. The mainstay of prevention is active immunization. However, less than $80 \%$ of infants in their first year were immunized in Camberwell, London between 1982 and 1984 (B. Evans, personal communication). Thus assumptions about immune status should not be made and an immunization history needs to be obtained in all cases with open skin injury $A \& E$ staff have a duty to ensure tetanus prevention as part of a patient's wound management and an individual's contact with A\&E department is an important way of maintaining levels of immunity in the community. This is particularly so in the inner city where uptake of immunization in young children is lower (Jarman et al., 1988).

We directed this study solely to the adequacy of active tetanus immunization given to patients with an open skin injury. While acknowledging their importance we did not examine adequacy of wound toilet or use of human anti-tetanus immunoglobulin.

Our department has followed the protocol of Smith et al. published in 1975. Chikhani \& Kumar (1988) have examined anti-tetanus antibody levels in the

Table 1. Effect of course triage.

\begin{tabular}{lccc}
\hline & $\begin{array}{c}\text { Tetanus not } \\
\text { mentioned } \\
\text { by nurse }\end{array}$ & $\begin{array}{c}\text { Tetanus } \\
\text { mentioned } \\
\text { by nurse }\end{array}$ & Total \\
\hline $\begin{array}{l}\text { Total } \\
\text { inadequately } \\
\text { treated }\end{array}$ & $97(53 \%)$ & $17(9 \%)$ & $114(24 \%)$ \\
$\begin{array}{l}\text { Correctly } \\
\text { treated }\end{array}$ & $80(44 \%)$ & $154(80 \%)$ & $234(49 \%)$ \\
& $7(4 \%)$ & $22(11 \%)$ & $29(6 \%)$ \\
$\begin{array}{l}\text { Excessive } \\
\text { treatment }\end{array}$ & 184 & 193 & $377(79 \%)$ \\
$\begin{array}{l}\text { Total } \\
\text { Uncertain' }\end{array}$ & & $102(21 \%)$ \\
\hline
\end{tabular}


community by a recently developed technique and suggest the intervals recommended by Smith et al. might safely be lengthened.

In this retrospective study we found less than half of the patients were correctly treated according to the protocol. At best this reflects poor recording practice, for our definition of correct treatment requires an adequate history and a note of it. At worst it shows incorrect management. A total of $6.1 \%$ were overtreated but nearly a quarter of patients may have received insufficient treatment.

By contrast we found that where the triage nurse mentioned tetanus on the record, nearly $80 \%$ were correctly questioned and treated. The triage nurse did not prevent excessive treatment, but prompting produced a striking improvement in the casualty officer's recording and management of these cases. This is an unexpected benefit of nurse triage.

Two recent studies of tetanus prophylaxis have been carried out in the USA (Brand et al., 1983; Giangrasso \& Smith 1985). Both were prospective whereas the present one was retrospective. Both included the administration of anti-tetanus immunoglobulin in their study which we did not. In comparing their results with ours account must be taken of the slightly different guidelines. If results pertaining to the use of toxoid alone are considered, Giangrasso's study shows $8.5 \%$ excessive immunization and $0.9 \%$ insufficient immunization. Brand's study shows $16 \cdot 1 \%$ excessive immunization and $3.4 \%$ insufficient immunization. It is interesting that the departments studied by Giangrasso used nurse triage and those studied by Brand did not.

In both American studies there was a greater degree of excessive treatment than in this study, but a similar incidence of the potentially more serious error of insufficient immunization.

Our incidence of $2.7 \%(14 / 479)$ represents proven errors. The true incidence of insufficient treatment may be higher but could not be obtained from our records. The smaller number of uncertain records in the American studies may be a reflection of the effect of a prospective investigation on recording practices.

Perhaps casualty officers still regard certain wounds as 'tetanus prone' even though there is considerable evidence to challenge the validity of this concept (American College of Surgeons Committee on Trauma, 1976) and the recommendations for active immunization of Smith $e t$ al. are identical for all open wounds. Our finding that four-fifths of patients with burns went untreated suggests that the out-dated idea of tetanus-prone wounds persists and that this might contribute to errors of insufficient treatment.

From clinical notes, we found that the casualty officers, individually or collectively, showed no evidence of learning over the 3-month interval. Tetanus prophylaxis instruction consisted of one formal tutorial, an induction course, a section in the department's practice manual containing the protocol and wall posters in the department. Although we did not evaluate the benefits from these forms of teaching in our department, the poor value of information brochures and posters in achieving closer adherence to a tetanus protocol has been noted previously (Edlich et al., 1986).

What further steps can be taken to improve protocol compliance to prevent tetanus? Some departments have a printed reference to tetanus on the casualty 
card. The value of this is unknown but could be revealed by Brand's finding that less than four-fifths of the patients in his study had adequate immunization history obtained although the physicians used a specific questionnaire protocol.

Failure to provide complete protection with current practice has led to a suggestion that the history be taken by admitting clerks and immunization be the responsibility of nursing staff (Editorial, 1984). In support of the latter, notes made during an initial nurse assessment had a very demonstrable impact in avoiding insufficient treatment in our study.

We recommend that tetanus immunoprophylaxis be a standard feature of nursing triage and that this in conjunction with specific feedback may have a greater $\overrightarrow{0}$ impact on compliance with treatment guidelines.

\section{REFERENCES}

American College of Surgeons (1976) Committee on Trauma. Early care of the injured patient, 2nd ed. 48-52 W.B. Saunders, Philadelphia.

Anon (1974) Reactions to tetanus toxoid. British Medical Journal 1, 48.

Anon (1984) Tetanus prophylaxis - do our guidelines assure protection? Journal of Trauma 24, 1063-4. $\frac{\mathbb{D}}{8}$

Brand D. A. Acampora D., Gottleib L. D., Glancy K. E. \& Frazier W. (1983) Adequacy of antitetanus prophylaxis in six hospital emergency rooms. New England Journal of Medicine 309, 636-40.

Community Physician, Camberwell, London, England.

Edlich R. E., Wilder B. J., Silloway K. A., Nichter L. S. \& Bryant C. A. (1986) Quality assessment $\vec{\theta} \vec{\bullet}$ tetanus prophylaxis in the wounded patient. The American Surgeon 52, 544-7.

Giangrasso J. \& Smith R. K. (1985) Misuse of tetanus immunoprophylaxis in wound care. Annals Emergency Medicine 14, 573-9.

Jarman B., Bosanguet N., Rice P., Dollimore N. \& Leese B. (1988) Uptake of immunisation in distric health authorities in England. British Medical Journal 296, 1775-78.

Public Health Laboratory Service; Communicable disease surveillance centre (1985) Tetanus surveillance: England and Wales, 1981-3 British Medical Journal 290, 696-7.

Smith J. W. G., Laurence D. R. \& Evans D. G. (1975) Prevention of tetanus in the wounded. British Medical Journal 3, 453-455. 